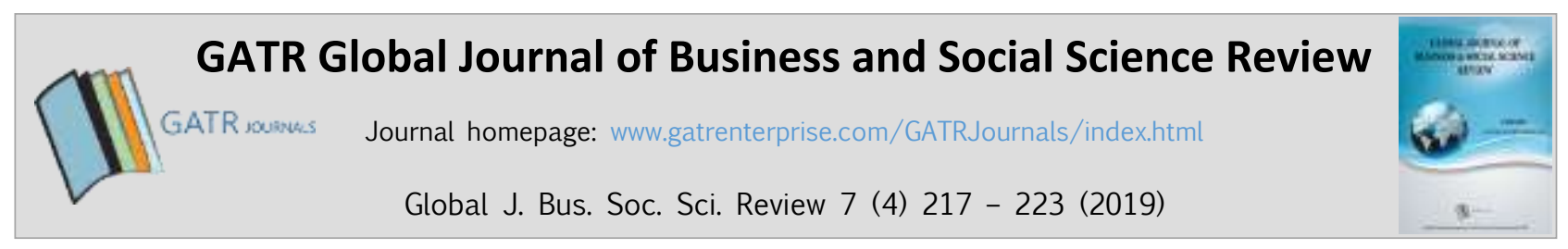

\title{
The Readiness of Small and Medium Enterprises for the Industrial Revolution 4.0
}

\author{
Shan Shan Teh ${ }^{1 *}$, Daisy Mui Hung Kee ${ }^{2}$ \\ ${ }^{12}$ Universiti Sains Malaysia, 11800, Penang, Malaysia
}

\begin{abstract}
Objective - The Industrial Revolution 4.0 has penetrated across the industrial world. It promotes innovation in organizing and controlling the entire value chain life cycle. The Industrial Revolution 4.0 not only brings convenience, but it also acts as a new trend toward smart technology. With this smart technology, production times are shortened, productivity is doubled, efficiency is increased, and income is also improved. The Industrial Revolution 4.0 is being emphasized among Malaysian SMEs. This is because SMEs constitute $98.5 \%$ of the business community in Malaysia. However, although the Industrial Revolution 4.0 is gaining popularity, SMEs remain relatively unaware on it. This has cast doubt on the readiness of Malaysian SMEs for the Industrial Revolution. Is the readiness of industrial revolution 4.0 reach the satisfaction level among Malaysian SMEs? Therefore, the purpose of this study is to assess the level of readiness of Malaysian SMEs for the Industrial Revolution 4.0. In addition, the study will also propose strategies to improve the readiness of SMEs in Malaysia for the Industrial Revolution 4.0.

Methodology/Technique - Various papers and current information was accessed to determine the readiness of Malaysia for the Industrial Revolution 4.0 and strategies that can be employed to enable SMEs to adopt the new era of industrial revolution.

Findings- From the findings it was concluded that Malaysian SMEs remain unprepared for the Industrial Revolution 4.0.

Novelty - This paper proposed important strategies to assist SMEs and employees to adapt to the Industrial Revolution 4.0.

Type of Paper: Review
\end{abstract}

Keywords: Readiness; Strategies; Small and Medium Enterprises; Industrial Revolution 4.0; Malaysia.

Reference to this paper should be made as follows: Teh, S. S; Kee D.M.H. (2019). The Readiness of Small and Medium Enterprises for the Industrial Revolution 4.0, Global J. Bus. Soc. Sci. Review 7(4): 217 - 223. https://doi.org/10.35609/gjbssr.2019.7.4(2)

JEL Classification: M20, M13, M19.

\section{Introduction}

The industrial revolution (IR) defines as the movement in which machines changed or altered the way people live as well as the methods of manufacture.

\footnotetext{
* Paper Info: Revised: September 17, 2019

Accepted: December 31, 2019

* Corresponding author: Shan Shan Teh

E-mail: shann_teh@hotmail.com

Affiliation: Universiti Sains Malaysia, 11800, Penang, Malaysia
} 
The development of the industry has been gradually changing throughout the years. IR 1.0 was introduced in Germany and had spread all around the world. It has started with the advent of steam and water power which enable mechanization of production processes in the end of the 18th century. When came to the year 1870, IR 2.0 was driven by electric power and mass manufacturing techniques. Information technology and automation brought in IR 3.0. Now, we are in the IR 4.0 which is focusing end-to-end digitization toward all the processes and integration into a digital ecosystem within the value chain (Hamidi, Aziz, Shuhidan, Aziz, $\&$ Mokhsin, 2018). With the concept of cyber-physical systems in IR 4.0, everything is about technology and it allows the two ways of communications between human and technology. This has resulted that the power of IR 4.0 cannot be overlooked.

IR 4.0 can bring lots of advantages to SMEs. By embracing IR 4.0, it promises an exponential increase in productivity as well as efficiency. This is due to the digitalization of the entire product lifecycle that will allow the organization to use data from production, service and even social media which leads to faster product improvement (MyForesight, 2018). For example, interaction and engagement between organizations and customers can be reached by using a social media platform which eventually will help in improving product development. Besides that, IR 4.0 allows SMEs to increase competitiveness. With the nine technological advances namely autonomous robots, augmented reality, big data and analytics, additive manufacturing, Industries Internet of Thing, horizontal and vertical system integration, cloud computing, simulation, and cybersecurity, these are able to solve the constraints faced by SMEs and eventually assists SMEs to compete for either in global or local markets (Gilchrist, 2016).

Nowadays, IR 4.0 is being emphasized among SMEs in Malaysia, this is because SMEs are constituting 98.5\% of business community in Malaysia. Based on the statistics of the SME survey, the real GDP growth has consistently outperformed the overall economy with the average annual growth rate at $6.6 \%$ compared to $5.2 \%$ for the overall growth of GDP in the period of 2011-2017 (SME Corp, 2018). In terms of SME employment, it has increased to $66.0 \%$ of total employment with a growth of $3.4 \%$ compared to $2.1 \%$ in 2016. Other than that, the SMEs' productivity continued to improve by $3.7 \%$ in 2017 with a value of RM63,167 compared to RM60,887 in 2016. Last but not least, SME exports recorded a higher growth of $7.9 \%$ compared to $7.0 \%$ in 2016 . Overall, with the statistics discussed above, SMEs act as a significant role in improving economic growth in Malaysia, especially in terms of growth of GDP, employment, labor productivity, and exports. SMEs are not only the enablers of growth as in the past but also a key driver of growth (SME Corp, 2018). Therefore, challenges or issues that are faced by SMEs cannot be neglected. Instead, support and assistance from the government or other agencies are crucial for Malaysian SMEs to drive them toward IR4.0.

In getting more importance of IR 4.0 toward SMEs, concerns have emerged among Malaysian SMEs. Are Malaysian SMEs ready in IR 4.0? What should be suggested toward SMEs to adapt IR 4.0? As of the findings, Malaysian SMEs are not yet ready in IR 4.0. The low adoption of digital automation in Malaysian SMEs has delayed the readiness and connectivity toward IR 4.0. It is reported that there are less than 50\% of automation being used by manufacturing firms (Miti, 2018). Therefore, digitalization should be a component that needs to be concerned among SMEs. In fact, Malaysian employees have the abilities and skillsets, but they require more training in understanding IR 4.0 which including automation technology and IT infrastructure (Hamidi et al., 2018). The knowledge of IR 4.0 is very important to lead employees in adapting IR 4.0. Thus, exclusive training and coaching that related to IR 4.0, knowledge in exchanging types of machinery and integrated systems are needed to their employees. Managers of SMEs should provide or encourage their employees to participate or join more training and coaching of IR 4.0. Hence, they can get adapt and ready toward IR 4.0 in a short time period.

\section{Literature Review}




\subsection{All about IR 4.0}

The term IR refers to the development process in the management of manufacturing and chain production. As now, we are in IR 4.0. Before IR 4.0 emerges, there were another three IRs namely IR 1.0, IR 2.0, and IR 3.0. IR 1.0 introduced machines into production by the end of the 18th century. With this introduction, the source of power was changed from manual production to steam and water power. The life of the human was getting convenience and comfortable. Besides that, IR 1.0 has assisted greatly in the agriculture and textile sectors. When it came to the year 1870-1914, IR 2.0 proposed electricity for mass production. Undeniably, IR 2.0 had enabled and contributed hugely to production rates. However, this IR 2.0 was put to the end when World War 1 started.

Next, IR 3.0 emerged in 1950 and 1970. IR 3.0 was using digital technology, electronics and informative system in the production. In IR 3.0, the human workers had been replaced by machines and robots on assembly lines. When comes to IR 4.0, it is a concept of cyber-physical systems. Everything is connecting to technologies, called the Internet of Things (IoT). The idea behind IR 4.0 is to create a social network with two ways of communication between humans and technologies. For example, in IR 3.0, television acts as a role to disseminate news to us, but in IR 4.0 television not only disseminate news to us, but it also plays a smart role to switch off itself when it senses that we are fallen sleep. Undeniably, the powerful of IR 4.0 has brought out a lot of smart technologies such as smartphones, smart homes, and smart cars (The Sun Daily, 25th December 2018).

\subsection{Benefits of IR4.0}

IR 4.0 will produce great benefits for all organizations. Optimizing production is one of the advantages that organizations will experience (Maskuriy, Selamat, Maresova, Krejcar, \& David, 2019). With the nine technological advances (namely, autonomous robots, augmented reality, big data and analytics, additive manufacturing, Industries Internet of Thing, horizontal and vertical system integration, cloud computing, simulation, and cybersecurity) IR 4.0 is able to encourage automation through autonomous robots and the Internet of Things which reduces the dependency on humans which can be error-prone. Big data and analytics enable SMEs to make use of the significant amount of data gathered and produce insights and business strategies. Machine learning can be used to better understand consumer behavior and customize marketing plans more proactively. Cloud computing enables SMEs to outsource IT services to cloud providers and focus on the business itself. Cybersecurity helps SMEs to ensure that their data, such as customer information, corporate secrets, and sensitive data are properly secured.

In short, self-optimized production will lead to almost zero downtime in production which is extremely crucial for industries. Moreover, it can improve the ability to manufacture various products at a higher speed and quality, as well as ensure greater efficiency. In addition, lowering operating cost is another benefit of IR 4.0. This is due to the higher level of automation in IR 4.0 which requires fewer employees and results in less wasted materials and more efficient operations. Thus, IR 4.0 can not only improve productivity and efficiency, but can reduce operating costs and eventually improve competitiveness. IR 4.0 will undoubtedly require a significant investment in implementing IT infrastructure in the first stages, but it will yield a big impact in the long term. SMEs will experience increased cost efficiency when IR 4.0 is fully implemented (SME Bank, 2017). 


\subsection{Challenges of IR4.0}

For Malaysian SMEs to be ready for IR 4.0, there are several challenges and impediments which need to be addressed. The most difficult challenge in embracing IR 4.0 is faced by manufacturing organizations in integrating digitalization to ensure that their stakeholders are aligned with the vision (SME Bank, 2017). This requires stakeholder engagement (Idris, 2019). Indeed, the sharing of information across the supply chain is not something new due to inter-connectivity between companies. However, it is important for SMEs who are different in nature compared to large corporations to realize that their venture into IR 4.0 requires leadership and change management.

Moreover, Malaysian SMEs lack awareness of the need and impact of IR 4.0 technologies (Miti, 2018). Many of them are still not fully aware of the importance and benefits of IR 4.0. The opportunities of IR 4.0 for SMEs such as new business models and frameworks, new production capabilities, faster delivery speed, better quality and monitoring, and innovations can help SMEs to increase their competitive advantage in their respective markets. It is therefore important that SMEs become more aware and prepare for the implementation of IR 4.0.

The low levels of digital automation in Malaysian SMEs also inhibits the readiness and connectivity toward IR 4.0 (Abidin et. al., 2018). Malaysian SMEs need to be more innovative in meeting customer expectations and demands. Therefore, it is crucial for SMEs to focus on innovation in order to provide customized products, fast delivery speeds, and good quality products to improve their competitiveness.

IR 4.0 also causes certain financial difficulties for Malaysian SMEs. The initial implementation of IR 4.0 requires a significant amount of investment by SMEs and in most cases, the financial return on that investment may take some time to realize (SME Bank, 2017). SMEs lack an understanding and analysis on how IR 4.0 brings values to the company in the long term, which results in their unwillingness to make a significant financial investment in IR 4.0.

\section{Research Methodology}

The methodology used for this paper includes evaluating online sources such as online newspapers and magazines, and previous literature reviews about the readiness of IR 4.0 among SMEs. The literature search of articles and journals is based on online databases which include Google, Google Scholar, Scopus, Science Direct, and Web of Science. Based on the online sources, the status of readiness for IR 4.0 was determined. In addition, the empirical studies show that Malaysia is still at the very beginning stages of becoming ready for the implementation of IR 4.0 (Abidin et. al., 2018; Idris, 2019; Omar \& Hasbolah, 2018). Some of the studies (Idris, 2019; Miti, 2018; SME Bank, 2017; Zaidi \& Belal, 2019) are also referred to in order to propose important strategies for Malaysian SMEs to prepare themselves for IR 4.0.

\section{Results}

\subsection{Status of Readiness of SMEs for IR 4.0}

The readiness of SMEs toward IR 4.0 can be defined as the ability to capitalize on future production opportunities, mitigate risks and challenges, and be resilient and agile in responding to unknown future shocks (Kearney, 2018). According to the report of the Readiness for the Future of Production Report 2018, Malaysia is in the "Leader" quadrant. It is also interesting to note that 
Malaysia and China are the only two countries in the "Leader" quadrant, who are not high-income countries. Yet, this assessment is based on two main components, namely, the structure of production and drivers of production. Structure of production is the current baseline of production, while drivers of production are the key enablers that position a country on IR 4.0. Furthermore, the World Economic Forum (WEF) also indicates that Malaysia's rankings in each of these drivers emphasize priorities in technology, human capital, and institutional frameworks that are consistent with some of the challenges highlighted previously (Kearney, 2018).

Other than that, according to the assessment of Hamidi et. al. (2018), the employees' skills and skill acquisition for IR 4.0 among Malaysian SMEs are in level 1, which is beginner. Indeed, employees have the skills however they lack knowledge of IR 4.0. The understanding and knowledge of employees about IR 4.0 is very important in adapting to the concept and strategy of IR 4.0. Therefore, Malaysian SMEs and the government should provide support to employees such as exclusive training seminars, knowledge transfer systems and coaching to prepare them for IR 4.0. Most Malaysian SMEs are in beginner status which is level 1 for the dimension of strategy and organization (Hamidi et. al., 2018). Strategy and organization is defined as innovation management, investments, and the strategy of an organization to move forward. Thus, the need for more understanding to move forward and plan accordingly in terms of IR 4.0 is very crucial for Malaysian SMEs.

In summary, Malaysian SMEs do not appear to be ready for IR 4.0. According to the Deputy of International Trade and Industry Minister Dr. Ong Kian Ming, many CEOs do not even know how to begin preparations for IR 4.0 and which aspect should be focused when the IR 4.0 is being emphasized (The Star, 5th April 2019). Based on the analysis carried out by the Bank of Negara Malaysia (2019), it was revealed that Malaysia as an adopter of IR 4.0 and the nation is leading in the region in terms of digital transformation, but Malaysia's economy still lags behind Japan and Singapore.

\subsection{Managerial Implications for Embracing IR 4.0}

SMEs are crucial components of the Malaysian economy, contributing 38.3\% of the growth of GDP in 2018 (The Star, 5th August 2019). Malaysian SMEs should be given increased attention for embracing IR 4.0. Therefore, different strategies are proposed for SMEs to ensure they are prepared for the adoption of IR 4.0.

First of all, a collaborative platform is needed among SMEs. Malaysian SMEs do not have a unified platform to share and contribute to the best practice and understanding of IR 4.0. Indeed, the platform must be centralized, organized, and contain easily accessible information to enable SMEs to understand how to be ready for IR 4.0. In addition, SMEs should collaborate and participate in broader production networks with other SMEs, multinational companies or large organizations (SME Bank, 2017). Thus, it is believed that a collaborative platform can help to improve the skills and knowledge by encouraging more collaborations among SMEs.

Moreover, training programs or workshops for employees should be provided. This is because there is a significant gap and shortage of IR 4.0 expertise, talents, skills, and knowledge such as artificial intelligence, data science, the Internet of Things, robotics, and machine learning. Employees of Malaysian SMEs need to participate in more skill enhancement training, conferences, and knowledge sharing events (Zaidi \& Belal, 2019). With these training programs being provided, 
employees can realize the importance of IR 4.0 and will eventually become aware of the skills and knowledge they require to embrace IR 4.0.

Last but not least, the digitalization of the manufacturing system is crucial. Digitalization can build a direct link to end customers in improving the satisfaction of customers and providing a better innovation product. For example, social media is a platform that can be utilized to engage or interact with customers to enhance customer expectations toward the products (Trainor, Andzulis, Rapp, \& Agnihotri, 2014). Furthermore, SMEs also need to practice an integrated and digital approach to gather and analyze the data due to the data volume, variety, velocity, veracity, and value. This may provide a better product which meets customers' expectation and eventually improve market competitiveness.

\section{Conclusion}

In conclusion, Malaysian SMEs are not yet prepared for the implementation of IR 4.0. Despite the enormous economic potential of IR 4.0, SMEs in the industry remain relatively unaware of it. SMEs must learn how to deal with these disruptions, be more resilient, and embrace the rate of change as an opportunity. IR 4.0 will have a significant impact on organizations and businesses in Malaysia. Thus, an exclusive platform or program is required to ensure that SMEs can transform more advanced manufacturing processes.

Indeed, SMEs have the skills to implement IR 4.0 however they lack knowledge to adapt and transform toward IR 4.0. An awareness campaign and training on IR 4.0 should be provided for SMEs. This may be able to assist SMEs to realize the importance of IR 4.0 and drive to IR 4.0 with confidence. It is interesting to note that IR 4.0 provides an opportunity for the small companies of today to become the giants of tomorrow.

\section{References}

Abidin, N. F. N. Z., Hasbolah, H., Mohamed, N., Khadri, R. R. R. D., Sidek, S., \& Wan, W. M. Y. Malaysian Technopreneur Issues and Challenges in 4th Industrial Revolution (4IR) Era. https://fkp.umk.edu.my/conference/iseb18/proceeding/p185u301c1-p481-490.pdf

Gilchrist, A. (2016). Industry 4.0: the industrial internet of things. Apress. https://books.google.com.pk/books?hl=en\&lr=\&id=YuOODAAAQBAJ\&oi=fnd\&pg=PP6\&dq=Gilchrist, + A.+(2016).+ Industry+4.0:+the+Industrial+Internet+of+Things.+New+York:+Apress.+\&ots=lnOmWkTWBT\&sig=JPSbgtNDUcd2xf-zAgo0cvaN-

g\&redir_esc $=\mathrm{y} \# \mathrm{v}=$ onepage $\& \mathrm{q}=$ Gilchrist $\% 2 \mathrm{C} \% 20 \mathrm{~A} . \% 20(2016) . \% 20$ Industry $\% 204.0 \% 3 \mathrm{~A} \% 20$ the $\% 20$ Industrial\%20Int ernet\%20of\%20Things.\%20New\%20York\%3A\%20Apress.\&f=false

Hamidi, S. R., Aziz, A. A., Shuhidan, S. M., Aziz, A. A., \& Mokhsin, M. (2018, March). SMEs maturity model assessment of IR4. 0 digital transformation. In International Conference on Kansei Engineering \& Emotion Research (pp. 721-732). Springer, Singapore.https://doi.org/10.1007/978-981-10-8612-0_75

Idris, R. (2019). Industrial Revolution 4.0: An Overview of Readiness and Potential Economic Effects in Malaysia from Millennial's $\quad$ Perspective. World $\quad$ Scientific News, $\quad 118, \quad 273-280$. http://psjd.icm.edu.pl/psjd/element/bwmeta1.element.psjd-cc6d508b-b2d8-4afb-bbc7-23d12284008a

Kearney, A. (2018). Readiness for the Future of Production Report 2018. Retrieved from http://www3.weforum.org/docs/FOP_Readiness_Report_2018.pdf

Maskuriy, R., Selamat, A., Maresova, P., Krejcar, O., \& David, O. O. (2019). Industry 4.0 for the Construction Industry: Review of Management Perspective. Economies, 7(3), 68. https://doi.org/10.3390/economies7030068

Miti. (2018). Industry 4WRD: National Policy on Industry 4.0. Kuala Lumpur: Ministry of International Trade and Industry. 
MyForesight. (2018). Global Driving Trends of Industry 4.0 (21st ed.). Cyberjaya, Selangor: Malaysian IndustryGovernment Group.

Omar, S. A., \& Hasbolah, F. (2018). Awareness and perception of accounting students towards industrial revolution 4.0. http://repo.uum.edu.my/26062/

SME Bank. (2017). Industry 4.0: Are Malaysian SMEs Ready? Kuala Lumpur: Small Medium Enterprise Development Bank Malaysia Berhad.

SME Corp. (2018). SME Annual Report 2017/18 - A Connected World: Digitalising SMEs. Retrieved from http://www.smecorp.gov.my/index.php/en/?option=com_content\&view=article\&layout=edit\&id=3342

The Star. (5th April 2019). SMEs Still Not Ready for Fourth Industrial Revolution. The Star. Retrieved from https:/www.thestar.com.my/business/business-news/2019/04/05/smes-still-not-ready-for-fourth-industrial-revolution

The Star. (5th August 2019). Higher SME Contribution to GDP. Retrieved from https://www.thestar.com.my/business/smebiz/2019/08/05/higher-sme-contribution-to-gdp

The Sun Daily. (25th December 2018). Malaysia must keep up with Revolution 4.0. The Sun Daily. Retrieved from https://www.thesundaily.my/local/malaysia-must-keep-up-with-revolution-4-0-CI309026

Trainor, K. J., Andzulis, J. M., Rapp, A., \& Agnihotri, R. (2014). Social media technology usage and customer relationship performance: A capabilities-based examination of social CRM. Journal of Business Research, 67(6), 12011208.https://doi.org/10.1016/j.jbusres.2013.05.002

Zaidi, M. F. A., \& Belal, H. M. (2019). A Preliminary Study To Understand The SMEs'readiness On Iot In Malaysia. International Journal of Accounting, Finance and Business (IJAFB), 4(19). http://researchonline.ljmu.ac.uk/id/eprint/10995/ 